\title{
Predictors of catheter-related bladder discomfort after gynaecological surgery
}

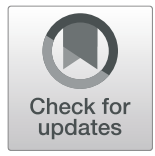

\author{
S. Y. Li, L. P. Song, Y. S. Ma ${ }^{*}$ and X. M. Lin
}

\begin{abstract}
Background: Urinary catheterization is universally used during surgery, and the incidence of postoperative catheter-related bladder discomfort (CRBD) is very high during recovery. We conducted this study to identify the incidence and predictors of postoperative CRBD after gynaecological surgery in the post-anesthesia care unit (PACU).

Methods: This was a prospective observational study. Patients undergoing gynaecological surgery under general anesthesia with intra-operative urinary catheterization were enrolled. We collected the clinical data, incidence and severity of CRBD, and postoperative pain for the patients. Predictive factors of CRBD were analysed by univariate and multivariate analysis.
\end{abstract}

Results: A total of 407 patients were included in this study. The incidence of CRBD after gynaecological surgery was 64.6\% (mild CRBD: 22.8\%; moderate CRBD: 34.2\%; and severe CRBD: 7.6\%). Univariate analysis showed that age, type of surgery, type of laparoscopic surgery, additional analgesics, and postoperative pain were influencing factors for CRBD. Based on multivariate logistic regression analysis, age $\geq 50$ years, uterus-related laparoscopic surgery, and lack of additional analgesics were independent predictors of moderate or severe CRBD.

Conclusions: This observational study revealed that the incidence of CRBD after gynaecological surgery in PACU was very high. Age $\geq 50$ years, uterus-related laparoscopic surgery, and lack of additional analgesics were independent predictors of CRBD.

Trial registration: ChiCTR1800016390. Registered on 30 May 2018.

Keywords: Catheter-related bladder discomfort, CRBD, Predictive factors

\section{Background}

Urinary catheterization is widely used to avoid bladder retention, allow urine output measurement and blood volume assessment in patients during surgery. A catheter located in the bladder may cause discomfort postoperatively, and this is called catheter-related bladder discomfort (CRBD). With the extensive use of catheters, the incidence of CRBD has been rising, ranging from 47 to $90 \%$ postoperatively $[1,2]$. The clinical manifestation of CRBD is

\footnotetext{
* Correspondence: maz0602@163.com

Department of Anesthesiology, West China Second Hospital of Sichuan University, Key Laboratory of Birth Defects and Related Diseases of Women and Children, Ministry of Education, No.20, Section 3, Renmin Nanlu, Chengdu, China
}

similar to that of an overactive bladder (OAB), including urinary urgency, urinary frequency with or without urge incontinence, or discomfort in the supra-pubic region [3]. CRBD is so distressing that it can increase postoperative agitation and pain, reduce satisfaction of personal hospital stay, and even increase the workload of medical staff. Therefore, it is helpful to identify predictive factors for CRBD and to enable preventive measures in clinical practice.

The major two independent predictors of CRBD are male gender and a Foley catheter diameter greater than or equal to $18 \mathrm{Fr}$ [1]. In addition, urinary catheterrelated pain $(\mathrm{UCRP}) \geq 4$, obstetric and gynaecological

(c) The Author(s). 2020 Open Access This article is licensed under a Creative Commons Attribution 4.0 International License, which permits use, sharing, adaptation, distribution and reproduction in any medium or format, as long as you give appropriate credit to the original author(s) and the source, provide a link to the Creative Commons licence, and indicate if changes were made. The images or other third party material in this article are included in the article's Creative Commons licence, unless indicated otherwise in a credit line to the material. If material is not included in the article's Creative Commons licence and your intended use is not permitted by statutory regulation or exceeds the permitted use, you will need to obtain permission directly from the copyright holder. To view a copy of this licence, visit http://creativecommons.org/licenses/by/4.0/ The Creative Commons Public Domain Dedication waiver (http://creativecommons.org/publicdomain/zero/1.0/) applies to the data made available in this article, unless otherwise stated in a credit line to the data. 
surgeries, and age $<50$ years are identified as postoperative risk factors for CRBD [4]. There is also a study showing that abdominal open surgery and a history of catheterization 3 months prior to the operation are independent predictors of CRBD after urological surgery [5].

Although obstetric and gynaecological surgeries have a higher incidence of CRBD, there is no study to date about the predictors of CRBD after gynaecological surgery. Therefore, we conducted this study to identify the incidence and predictors of postoperative CRBD after gynaecological surgery in the post-anesthesia care unit (PACU).

\section{Methods}

This prospective observational study was approved by the China Ethics Committee of Registering Clinical Trials, and registered in the Chinese Clinical Trial Registry (ChiCTR1800016390). It was implemented in West China Second Hospital of Sichuan University from June to July 2018. The selection criteria included age $\geq 18$ years, elective gynaecological operation which were not associated with intra-operative injury to the urinary tract or intestinal tract, requiring bladder catheterization. The exclusion criteria included patients with a history of $\mathrm{OAB}$, bladder outflow obstruction, neurogenic bladder, preoperative urinary tract infection, or unable to communicate.

General anesthesia was implemented using a standardized approach in our hospital. Anesthesia was induced with midazolam, sufentanil, propofol, muscle relaxants, and maintained with sevoflurane or propofol. Lornoxicam and tramadol were common used as additional analgesia administered near the end of operation for postoperative pain according to anesthetists' own habit without consideration of the effects on CRBD. Neostigmine and atropine were used to antagonize the residual effects of muscle relaxants. All patients received a 16-Fr Foley urinary catheter with $10 \mathrm{~mL}$ normal saline inflating the catheter balloon.

After tracheal extubation in the operating room, all patients were transferred to the PACU for further recovery. In the PACU, we collected clinical data for the patients, including age, sufentanil dosage, surgery duration time, type of surgery, type of laparoscopic surgery, occasion of catheterization (before anaesthesia or after anaesthesia), additional analgesics near the end of the operation, intraoperative atropine, and postoperative neostigmine and atropine. We classified gynaecological surgery into three types: laparoscopic surgery, open abdominal surgery, and cervical conization and pelvic reconstructive surgery. The laparoscopic surgery was classified as uterus-related laparoscopic surgery and non-uterine related laparoscopic in detail. We also evaluated the severity of CRBD and postoperative pain.
Patients were instructed to differentiate CRBD from incisional or surgical pain.

The severity of CRBD was assessed as follows: none, did not report any CRBD even when asked; mild, revealed only on questioning; moderate, complained on their own without questioning but not accompanied with any behavioral response; severe, stated on their own and followed by behavioral responses such as strong verbal response, flailing limbs, or even try to pull out the urinary catheter. Postoperative pain was recorded as a visual analogue scale (VAS) score with 10 points.

Patients were divided into groups according to the incidence and severity of CRBD.

The incidence group was CRBD $\geq 1$ (mild, moderate and severe), while the severity group was $C R B D \geq 2$ (moderate and severe). Categorical variables were analyzed by the chi-square test and Fisher's exact test. Multivariate logistic regression was used to assess predictors with $P<0.05$ in univariate analysis. All the data were analyzed by using SPSS 17.0 , and $\mathrm{P}<0.05$ was considered significant.

\section{Results}

A total of 407 patients who underwent elective gynaecological surgery were included in this study. The incidence of CRBD was $64.6 \%$, and the occurrence of moderate or severe CRBD was $41.8 \%$ in the PACU (Table 1). Patient characteristics are listed in Table 2. Univariate analysis showed age $\geq 50$ years, cervical conization and pelvic surgery, uterus-related laparoscopic surgery, lack of additional analgesics, and VAS $\geq 4$ to be predictive factors of CRBD (Table 3). In addition, multivariate logistic regression analysis showed that age $\geq 50$ years and uterus-related laparoscopic surgery were independent predictors of the incidence of CRBD; and that age $\geq 50$ years, uterus-related laparoscopic surgery, and lack of additional analgesics were independent predictors of moderate or severe CRBD (Table 4).

\section{Discussion}

According to this observational study, the incidence of CRBD after gynaecological surgery was $64.6 \%$, and the occurrence of moderate or severe CRBD was $41.8 \%$. Age $\geq 50$ years, uterus-related laparoscopic surgery, and

Table 1 Incidence and severity of CRBD after gynecological sugery in PACU. Data are expressed as number of patients (\%)

\begin{tabular}{ll}
\hline CRBD & $\mathrm{n}(\%)$ \\
\hline NO & $144(33.4 \%)$ \\
Mild & $93(22.8 \%)$ \\
Moderate & $139(34.2 \%)$ \\
Severe & $31(7.6 \%)$ \\
\hline
\end{tabular}


Table 2 Patient characteristics. Incidence of CRBD: CRBD $\geq 1$, and severity CRBD: CRBD $\geq 2$

\begin{tabular}{|c|c|c|c|c|c|c|c|c|}
\hline & CRBD $\geq$ & & CRBD $<$ & & CRBD $\geq$ & & CRBD & \\
\hline & Mean & SD & Mean & SD & Mean & SD & Mean & SD \\
\hline Age & 44.3 & 12,6 & 39.0 & 12.1 & 44.4 & 11.8 & 41.0 & 13.1 \\
\hline Height & 159.9 & 28.5 & 157.9 & 9.9 & 158.3 & 5.0 & 159.8 & 30.7 \\
\hline Weight & 58.1 & 8.5 & 57.4 & 12.2 & 58.4 & 8.6 & 57.5 & 10.8 \\
\hline Sufentanil dosage & 22.4 & 6.5 & 22.7 & 7.1 & 22.3 & 6.2 & 22.7 & 7.1 \\
\hline Surgery duration time & 122.6 & 68.8 & 125.4 & 84.2 & 122.3 & 65.2 & 124.5 & 80.7 \\
\hline Postoperative pain & 3.4 & 1.5 & 2.8 & 1.8 & 3.6 & 1.4 & 2.9 & 1.8 \\
\hline
\end{tabular}

Table 3 Univariate analysis for predictive factors of the incidence of CRBD (CRBD $\geq 1)$ and the severity CRBD (CRBD $\geq 2)$. Data are presented as number (\%)

\begin{tabular}{|c|c|c|c|c|c|}
\hline Variable & $n$ & CRBD $\geq 1$ (incidence) & $P$ & $C R B D \geq 2$ (severity) & $P$ \\
\hline \multicolumn{6}{|l|}{ Age } \\
\hline$\geq 50 y$ & 100 & $78(78.0)$ & 0.001 & $51(51.0)$ & 0.031 \\
\hline$<50 y$ & 307 & $185(60.3)$ & & 119 (38.8) & \\
\hline \multicolumn{6}{|l|}{ Sufentanil dosage } \\
\hline$>20 \mu \mathrm{g}$ & 180 & $121(67.2)$ & 0.328 & $78(43.4)$ & 0.569 \\
\hline$\leq 20 \mu \mathrm{g}$ & 227 & $142(62.6)$ & & $92(40.5)$ & \\
\hline \multicolumn{6}{|l|}{ Surgery duration time } \\
\hline$>180 \mathrm{~min}$ & 90 & $56(62.2)$ & 0.59 & $32(35.6)$ & 0.176 \\
\hline$\leq 180 \min$ & 317 & $207(65.3)$ & & $138(43.5)$ & \\
\hline \multicolumn{6}{|l|}{ Type of surgery: } \\
\hline Laparoscopic surgery & 278 & $175(62.9)$ & 0.009 & $115(41.4)$ & 0.032 \\
\hline Open abdominal surgery & 80 & $47(58.8)$ & & $27(33.8)$ & \\
\hline Cervical conization and pelvic reconstructive surgery & 49 & $41(83.7)$ & & $28(57.1)$ & \\
\hline \multicolumn{6}{|l|}{ Type of laparoscopic surgery: } \\
\hline Uterus-related laparoscopic surgery & 158 & $113(71.5)$ & 0.002 & $78(49.4)$ & 0.004 \\
\hline Non-uterine related laparoscopic surgery & 121 & $66(54.5)$ & & $40(33.0)$ & \\
\hline \multicolumn{6}{|l|}{ Occasion of catheterization: } \\
\hline Before anaesthesia & 68 & $39(57.4)$ & 0.170 & $22(32.4)$ & 0.085 \\
\hline After anaesthesia & 339 & $224(66.1)$ & & $148(43.7)$ & \\
\hline \multicolumn{6}{|l|}{ Additional analgesics: } \\
\hline Yes & 54 & $25(46.3)$ & 0.002 & $11(20.4)$ & 0.001 \\
\hline No & 353 & $238(67.4)$ & & $159(45.0)$ & \\
\hline \multicolumn{6}{|l|}{ Intraoperative atropine: } \\
\hline Yes & 121 & $84(69.4)$ & 0.188 & $55(45.5)$ & 0.327 \\
\hline No & 286 & $179(62.6)$ & & $115(40.2)$ & \\
\hline \multicolumn{6}{|l|}{ Postoperative neostigmine and atropine: } \\
\hline Yes & 54 & $35(64.8)$ & 0.974 & $25(46.3)$ & 0.469 \\
\hline No & 353 & $228(63.6)$ & & $145(41.1)$ & \\
\hline \multicolumn{6}{|l|}{ Postoperative pain: } \\
\hline VAS $\geq 4$ & 139 & $100(71.9)$ & 0.026 & $70(50.4)$ & 0.011 \\
\hline VAS $\leq 3$ & 268 & $163(60.8)$ & & $100(37.3)$ & \\
\hline
\end{tabular}


Table 4 Multivariate logistic regression analysis for predictive factors of the incidence of CRBD (CRBD $\geq 1)$ and the severity of $C R B D$ $(\mathrm{CRBD} \geq 2)$

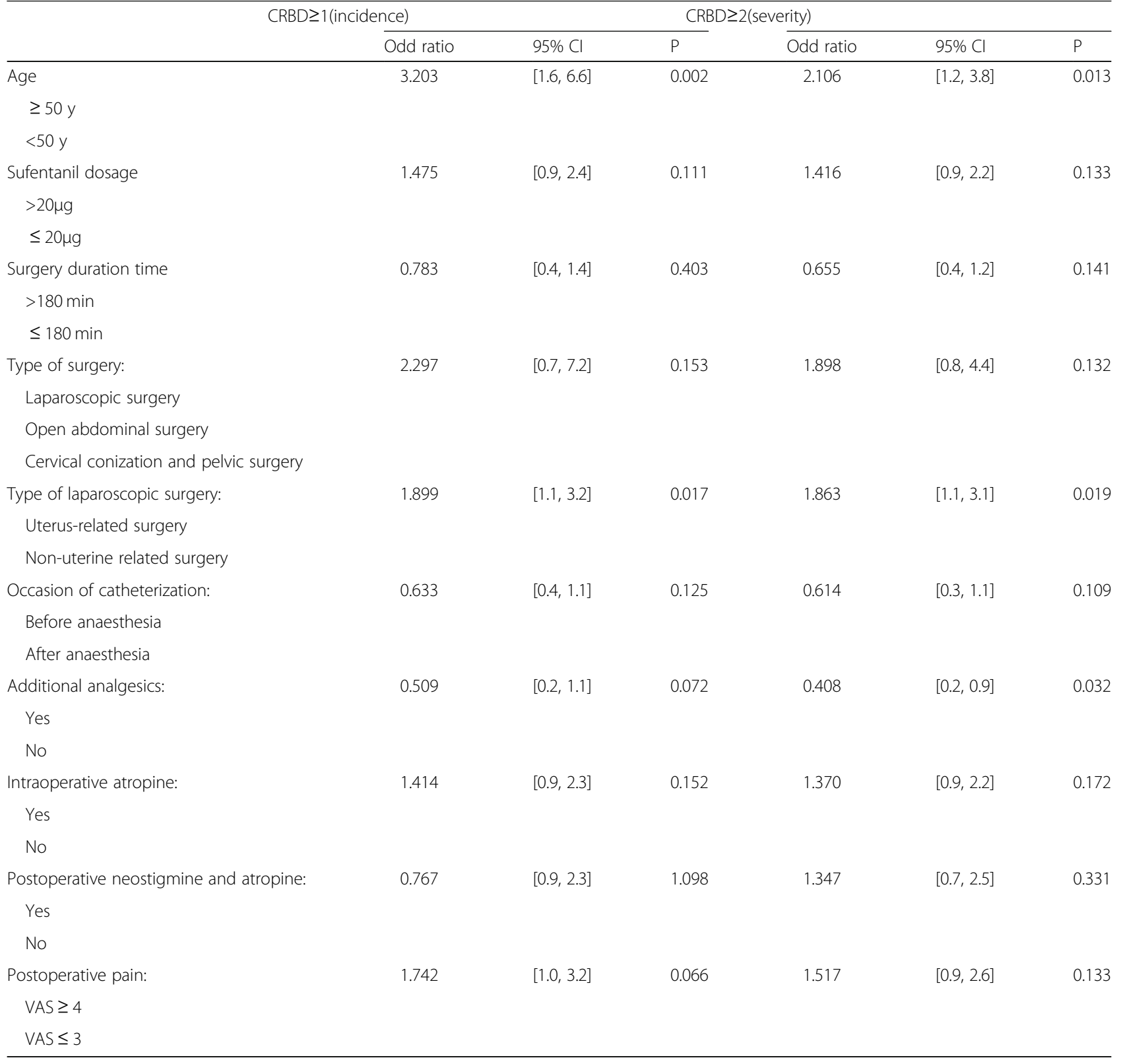

lack of additional analgesics might be the independent predictive factors of CRBD after gynaecological surgery.

Age $\geq 50$ year was associated with a higher incidence and severity of CRBD in our study, in contrast to the results of Lim's study [4]. In gynaecological surgery, more malignant lesions and hysterectomy-related surgery in older people have been reported, with more benign lesions and non-hysterectomy-related surgery in younger individuals. This was consistent with our finding that hysterectomy-related laparoscopic surgery was correlated with a higher incidence and severity of CRBD than was non-hysterectomy-related laparoscopic surgery.
Because the uterus is adjacent the bladder, placement of the uterine manipulator is likely to stimulate the bladder during hysterectomy-related laparoscopic surgery. In addition, postoperative loss of peripheral tissue support can easily induce bladder paralysis. Furthermore, postoperative surgical-site pain might aggravate CRBD.

Cervical conization and pelvic reconstructive surgery resulted in a higher incidence and severity of CRBD. This might be related to the surgical procedures, whereby pulling the urethra to expose the vagina and cervix might stimulate the urethra intra-operatively, and the oil gauze/ iodophor gauze filling the cervix/vagina 
may compress the urethra postoperatively. Our study also showed that additional analgesics administered near the end of the operation and postoperative pain VAS $\leq 3$ were associated with a lower incidence and severity of CRBD. Studies have reported that tramadol and nonsteroid anti-inflammatory drugs are effective for managing CRBD [6, 7]. Moreover, patients might confuse surgery-related pain with urinary catheter-related pain.

The mechanism of CRBD is due to the disordered bladder contraction mediated by muscarinic receptors, especially subtype M3 receptors [8]. Various antimuscarinic agents, such as tolterodine, oxybutynin, butylscopolamine, ketamine, tramadol, and dexmedetomidine, have been employed to reduce CRBD with varying degrees of success [9-15]. Nonetheless, these drugs also have some adverse effects, such as dry mouth, sedation, nausea, and vomiting. Thus, we should weigh the advantages and disadvantages of CRBD and adopt a multimode comprehensive prevention and control method to manage it. These methods include lubricating oil, local anesthetics, psychological intervention, drug prevention (used for high-risk patients: male gender, urological surgery, or obstetric and gynaecological surgery), and medical treatment (needed for moderate or severe CRBD postoperatively). Previous report suggested that sevoflurane with antimuscarinic effect decrease the incidence of CRBD [16]. As our hospital conventionally used sevoflurane inhalation to maintain anesthesia, the including patients in this study were all used sevoflurane.

This study has some limitations. First, we only evaluated the incidence and severity of CRBD in the PACU, but we did not perform further evaluation in the ward, some issues with CRBD might occur after PACU and on the ward. Besides, the size of urinary catheter is a risk factor of CRBD. In this study, $16 \mathrm{Fr}$. Urinary Catheter was used in all patients. The high incidence of CRBD in this investigation may be related to the big-sized urinary catheter. Moreover, we did not observe the post-operative urinary tract infection. There was a certain imbalance in the primary data, such as type of surgery, additional analgesics, and occasion of catheterization. For example, there was more laparoscopic surgery and less cervical conization and pelvic reconstructive surgery in our hospital. The patients used additional analgesics and catheterized before anaesthesia were also less.

\section{Conclusion}

This observational study revealed that the incidence of CRBD after gynaecological surgery in PACU was very high. Age $\geq 50$ years, uterus-related laparoscopic surgery, and lack of additional analgesics were independent predictors of CRBD.

\section{Abbreviations}

CRBD: catheter-related bladder discomfort; PACU: post-anesthesia care unit; OAB: overactive bladder; UCRP: urinary catheter-related pain; VAS: visual analogue scale

\section{Acknowledgements \\ Not applicable.}

\section{Authors' contributions}

LSY: study design, data collection, data analysis and writing paper. SLP: data collection. MYS: study design, data analysis and manuscript revision. LXM: Study design and manuscript revision. All authors read and approved the final manuscript.

\section{Funding}

No funding.

\section{Availability of data and materials}

The datasets are not publicly available, but available from the corresponding author on reasonable request.

\section{Ethics approval and consent to participate}

Ethical approval was obtained from China Ethics Committee of Registering Clinical Trials (ChiECRCT-20180059), address: West China Hospital, Sichuan University, NO. 37, Guo Xue Xiang, Chengdu, Sichuan, China. The trial was registered in the Chinese Clinical Trial Registry (ChiCTR1800016390, date of registration: 2018-5-30) prior to patient enrollment. Written informed consent was abtained from all patients.

\section{Consent for publication}

Not applicable.

\section{Competing interests}

The authors declare that they have no competing interests.

Received: 25 March 2019 Accepted: 19 April 2020

Published online: 28 April 2020

References

1. Binhas M, Motamed C, Hawajri N, Yiou R, Martly J. Predictors of catheterrelated bladder discomfort in the postanaesthesia care unit. Ann Fr Anesth Reanim. 2011;30:122-5.

2. Bai Y, Wang X, Li X, et al. Management of catheter-related bladder discomfort in patients who underwent elective surgery. J Endourol. 2015;29: 640-9.

3. Andersson KE. The pharmacology of lower urinary tract smooth muscles and penile erectile tissues. Pharmacol Rev. 1993;45:253-308.

4. Lim N, Yoon H. Factors predicting catheter-related bladder discomfort in surgical patients. J Perianesth Nurs. 2017;32:400-8.

5. Li C, Liu Z, Yang F. Predictors of catheter-related bladder discomfort after urological surgery. J Huazhong Univ Sci Technolog Med Sci. 2014;34:559-62.

6. Agarwal A, Yadav G, Gupta D, Singh PK, Singh U. Evaluation of intraoperative tramadol for prevention of catheter-related bladder discomfort: a prospective, randomized, double-blind study. Br J Anaesth. 2008;101:506-10.

7. Agarwal A, Dhiraaj S, Pawar S, Kapoor R, Gupta D, Singh P. An evaluation of the efficacy of gabapentin for prevention of catheter-related bladder discomfort: a prospective, randomized, placebocontrolled, double-blind study. Anesth Analg. 2007;105:1454-7.

8. Igawa Y. Discussion: functional role of $M(1), M(2)$, and $M(3)$ muscarinic receptors in overactive bladder. Urology. 2000;55(5A Suppl):47-9.

9. Agarwal A, Raza M, Singhal V, et al. The efficacy of tolterodine for prevention of catheter-related bladder discomfort: a prospective, randomized, placebo-controlled, double-blind study. Anesth Analg. 2005; 101:1065-7.

10. Tauzin-Fin P, Sesay M, Svartz L, Krol-Houdek MC, Maurette P. Sublingual oxybutynin reduces postoperative pain related to indwelling bladder catheter after radical retropubic prostatectomy. Br J Anaesth. 2007;99:572-5.

11. Agarwal A, Dhiraaj S, Singhal V, Kapoor R, Tandon M. Comparison of efficacy of oxybutynin and tolterodine for prevention of catheter related bladder 
discomfort: a prospective, randomized, placebo-controlled, double-blind study. Br J Anaesth. 2006;96:377-80.

12. Nam K, Seo JH, Ryu JH, et al. Randomized, clinical trial on the preventive effects of butylscopolamine on early postoperative catheterrelated bladder discomfort. Surgery. 2015;157:396-401.

13. Shariat MR, Lajevardi M, Khajavi M, Najafi A, Shariat MG, Etezadi F. Effects of intra-operative ketamine administration on postoperative catheter-related bladder discomfort: a double-blind clinical trial. Pain Pract. 2014;14:146-50.

14. Li S, Song L, Ma Y, Lin X. Tramadol for the treatment of catheter-related bladder discomfort: a randomized controlled trial. BMC Anesthesiol. 2018; 18(1):194.

15. Kim HC, Lee YH, Jeon YT, et al. The effect of intraoperative dexmedetomidine on postoperative catheter-related bladder discomfort in patients undergoing transurethral bladder tumour resection: a double-blind randomised study. Eur J Anaesthesiol. 2015;32:596-601.

16. Kim HC, Park HP, Lee J, Jeong MH, Lee KH. Sevoflurane vs. propofol in postoperative catheter-related bladder discomfort: a prospective randomized study. Acta Anaesthesiol Scand. 2017;61:773-780.

\section{Publisher's Note}

Springer Nature remains neutral with regard to jurisdictional claims in published maps and institutional affiliations.

Ready to submit your research? Choose BMC and benefit from:

- fast, convenient online submission

- thorough peer review by experienced researchers in your field

- rapid publication on acceptance

- support for research data, including large and complex data types

- gold Open Access which fosters wider collaboration and increased citations

- maximum visibility for your research: over $100 \mathrm{M}$ website views per year

At BMC, research is always in progress.

Learn more biomedcentral.com/submissions 